\title{
Ecuador: ciberperiodismo de investigación y agenda de la cooperación internacional
}

\section{Ecuador: Research cyberjournalism and international cooperation agenda}

\section{Equador: ciberjornalismo de pesquisa e agenda de cooperação internacional}

\author{
Saudia Levoyer Salas ${ }^{1}$ \\ Universidad Andina Simón Bolívar (Ecuador) \\ saudia.levoyer@uasb.edu.ec \\ Pablo Escandón Montenegro \\ Universidad Andina Simón Bolívar (Ecuador) \\ pablo.escandon@uasb.edu.ec
}

Fecha de recepción: 20 de abril de 2019

Fecha de recepción evaluador: 30 de abril de 2019

Fecha de recepción corrección: 10 de mayo de 2019

\footnotetext{
1 Saudia Levoyer Salas, Directora del Área de Comunicación de la Universidad Andina Simón Bolívar, Sede Ecuador. Comunicadora Social por la Universidad Central del Ecuador. Periodista y editora en varios medios de comunicación nacionales como El Comercio, Hoy, Revista Vanguardia, Blanco y Negro. Corresponsal de prensa extranjera. Licenciada en Comunicación Social, Universidad Central del Ecuador, Quito; Magíster en Estudios Latinoamericanos, con mención en Estudios de la Cultura, Universidad Andina Simón Bolívar, Sede Ecuador, Quito; Doctora en Comunicación e Información Contemporánea, Universidad de Santiago de Compostela. https://orcid.org/0000-0003-3708-751X

2 Pablo Escandón Montenegro, Comunicador social y escritor de ficción. Doctor en Comunicación e Información Contemporánea (Universidad de Santiago de Compostela - España), enfocado en temas de patrimonio, museos, recuperación de memoria y literatura digital. Docente de grado y postgrado en varias universidades del Ecuador. Docente a tiempo completo del área de Comunicación de la Universidad Andina Simón Bolívar, sede Ecuador. https://orcid.org/0000-0001-7806-6657
} 


\title{
Resumen
}

En el Ecuador, las plataformas digitales de investigación periodística han surgido debido al apoyo de la cooperación internacional y sus líneas de interés, principalmente, debido a que durante el decenio 2007-2017, la información en los medios tradicionales tuvo un control directo desde el Estado, por lo cual las unidades de investigación periodística vieron disminuidas sus labores y hasta se extinguieron. A pesar de tener el recurso humano formado, las empresas periodísticas no apostaron más por la investigación, por lo cual los periodistas trasladaron su quehacer a espacios digitales especializados temáticamente, y que son financiados por la cooperación internacional y sus líneas primordiales de trabajo: lucha contra la corrupción, crimen organizado y trata de personas; lo cual ha hecho que la investigación periodística haya salido de los medios tradicionales y se desarrolle en estos espacios de ciberperiodismo especializado, en donde la agenda no se plantea desde una necesidad próxima sino desde una visión global o bien desde un requerimiento externo, pero que incide en la realidad social del país. Se analizarán la agenda setting de Plan V (www.planv.com.ec), Código Vidrio (www.codigovidrio.com) y Mil hojas (www.milhojas.is) para establecer su relación con la agenda de los cooperantes internacionales.

Palabras clave: ciberperiodismo, cooperación internacional, investigación periodística, agenda setting, ética.

\begin{abstract}
In Ecuador, digital journalism research platforms have emerged due to the support of international cooperation and its lines of interest, mainly because during the 2007-2017 decade, information in traditional media had direct control from the State, which is why the journalistic investigation units saw their work diminished and even died out. Despite having a trained human resource, the journalistic companies did not bet more for the investigation, for which the journalists transferred their work to thematic specialized digital spaces, and which are financed by international cooperation and its main lines of work: fight against corruption, organized crime and trafficking in persons; which has made that the journalistic investigation has left the traditional media and develops in these spaces of specialized cyberjournalism, where the agenda does not arise from a near need but from a global vision or from an external requirement, but that affects in the social reality of the country. The agenda setting of Plan V (www.planv.com.ec), Código Vidrio (www.codigovidrio.com) and Mil hojas (www.milhojas.is) will be analyzed to establish its relationship with the agenda of international donors.
\end{abstract}

Keywords: Cyberjournalism, international cooperation, research journalism, agenda setting, ethics.

\section{Resumo}

No Equador, surgiram plataformas de pesquisa em jornalismo digital devido ao apoio à cooperação internacional e suas linhas de interesse, principalmente porque durante a 
década 2007-2017, as informações na mídia tradicional tiveram controle direto do Estado, razão pela qual as unidades de investigação jornalística viram o trabalho deles diminuiu e até desapareceu. Apesar de contar com recursos humanos treinados, as empresas jornalísticas não apostaram mais na investigação, pela qual os jornalistas transferiram seu trabalho para espaços digitais especializados temáticos e financiados pela cooperação internacional e suas principais linhas de trabalho: combate à corrupção, organização crime e tráfico de pessoas; que fez com que a investigação jornalística deixasse a mídia tradicional e se desenvolvesse nesses espaços do ciberjornalismo especializado, onde a agenda não surge de uma necessidade próxima, mas de uma visão global ou de um requisito externo, mas que afeta a realidade social de o país. A definição da agenda do Plano V (www.planv.com.ec), Código Vidrio (www.codigovidrio.com) e Mil hojas (www.milhojas.is) será analisada para estabelecer sua relação com a agenda de doadores internacionais.

Palavras-chave: Ciberjornalismo, cooperação internacional, jornalismo de pesquisa, definição de agenda, ética.

\section{Introducción}

De acuerdo con el estudio de Ana Gabriela Cazar (2017) sobre los retos del periodismo digital en Ecuador, al año 2017, el país contaba con un total de 49 medios digitales nativos, y para marzo de 2019 ya son 60 los cibermedios que desarrollan contenido exclusivamente en plataformas que no comparten con medios tradicionales (Morán, 2019).

Este crecimiento de espacios y plataformas mediáticas destinadas a la información y la creación de contenido periodístico tiene varias causas, además de las que estudian autores como Salaverría, Negredo, Díaz Noci o López, para mencionar algunos de los más destacados autores de ciberperiodismo en habla hispana.

Ecuador tiene la particularidad de que, en la última década, la relación entre el gobierno y los medios estuvo signada por confrontaciones legales, personales e ideológicas, lo que llevó a que varios trabajos periodísticos dejaran de funcionar en su plataforma madre, principalmente impresa, y optar por la digital, con las limitaciones de conocimiento y aptitudes de los periodistas en este tema.

La Ley Orgánica de Comunicación (2013) no considera a los medios digitales como espacios similares de producción y difusión como los tradicionales, razón por la cual, muchos de estos espacios de desarrollo del ciberperiodismo no tienen acceso a la publicidad oficial, además porque no son parte del registro mediático realizado por las instancias estatales de control y desarrollo de la comunicación.

Con estos antecedentes, el ciberperiodismo en Ecuador ha tenido que recurrir, como modelo económico, a la provisión externa de fondos concursables que ofrecen agencias internacionales de cooperación en torno a temas puntuales de trabajo 
periodístico como libertad de expresión, anticorrupción, derechos humanos, entre otras líneas de trabajo.

El presente trabajo es el avance de una investigación que tiene la finalidad de confrontar cómo los espacios digitales Plan V (www.planv.com.ec), Código Vidrio (www.codigovidrio.com) y Mil hojas (www.milhojas.is), todos de investigación en temas de corrupción estatal, establecen sus agendas periodísticas y encuadres con relación a la de los cooperantes internacionales, y de esta manera aportan a su modelo de sostenibilidad económica.

\section{Metodología}

Para el desarrollo del presente trabajo se aplicó una entrevista estructurada a los editores de dos de los tres cibermedios estudiados: Mil hojas (Christian Zurita) y Código Vidrio (Arturo Torres), quienes contestaron el cuestionario mediante una entrevista personal; así como a los principales de las organizaciones que gestionan fondos externos para la formación de periodistas en el país: Fundamedios (Desireé Yépez y César Ricaurte) y Foro de Periodistas del Ecuador (Pamela Cruz).

El estudio cualitativo es importante para confrontar los temas de independencia editorial y asimilación a los lineamientos de la financiación externa para investigar casos de corrupción, principalmente. De esta manera, los entrevistados reflexionaron acerca de la situación del periodismo digital y sus vertientes de innovación, modelo de negocio y formas de trabajo, así como reputación del cibermedio.

Para analizar los casos de estudio: Mil Hojas y Código Vidrio, se hace una descripción formal del cibermedio y la reputación de sus periodistas asociados, ya que esta es una variable importante al momento de entregar la información entre su audiencia, a partir de los diez puntos que establece Campos Freire (2015).

\section{Periodismo digital modelos de negocio y cooperación internacional}

\section{Modelos de negocio y cibermedios}

López y Pereira (2008) anotan que el cambio de los modelos negocio en la prensa, tanto impresa como digital, es vertiginoso, lo cual ha cambiado los procesos de producción, distribución y, principalmente, de consumo y relación con los usuarios, por lo cual la personalización e individualización de la información es una de las principales estrategias para captar nuevos usuarios o mantener a los existentes.

Si bien no existe un modelo único de economía y sustentabilidad de negocio en la prensa digital (López y Pereira, 2008: 186-187), la competitividad, la convergencia, la movilidad, la interactividad, la participación y la reputación son elementos importantes al momento de establecer nuevos modelos de negocio en los cibermedios.

John Pavlik (2008) describe los modelos de negocio en la prensa digital a partir de lo que Robert Picard describe y se fundamenta en cuatro formas de ingreso: la 
publicidad, el patrocinio, medios digitales por demanda y pago por contenido. Además, Pavlik establece formas alternativas de financiamiento que mezclan los modelos de acuerdo a sus audiencias, modos de producción y plataforma de difusión de sus contenidos.

Los modelos de negocio de los medios digitales aún siguen en transformación y no hay ninguna fórmula estable (Pavlik, 2008: 173), pero ya en 2014, el propio Picard (Campos Freire, 2015) vislumbró que el modelo de pago sería una luz positiva para los cibermedios, pues sería un equilibrio entre las ganancias para los financistas y trabajadores del medio digital y el servicio público a la sociedad que entregan los productores de la información periodística.

Los modelos de negocio de los cibermedios están relacionados con sus niveles o grados de innovación, como lo establecen Portilla Manjón, Vara-Miguel y Díaz-Espina (2016), pues es imposible desligar estas dos variables al desarrollo del periodismo digital y su sustentabilidad empresarial.

Para estos autores (Portilla Manjón, Vara-Miguel y Díaz-Espina, 2016: 34-35), los elementos de un modelo de negocio para medios digitales deben ser analizados desde la propuesta de valor, la segmentación de mercado, las estrategias de crecimiento y las capacidades institucionales como sociedad para poder llevar a cabo todo lo anterior. Por lo tanto, la propuesta de valor del cibermedio y su incidencia en los usuarios es un elemento crucial al momento de generar el modelo de negocio y establecer los tipos de innovación tecnológica o de producción y distribución que se tendrá.

Desde el punto de vista de procesos productivos de información, Portilla Manjón, Vara-Miguel y Díaz-Espina (2016:35) también se refieren a los tipos de modelos de ingreso por contenidos digitales desarrollados por Picard (Pavlik, 2008): el modelo publicitario para audiencias masivas para los anunciantes, el modelo de ingresos por pago, ya sea mediante suscripción, acceso parcial a los contenidos o acceso privilegiado a mayor información, aquí tenemos el modelo de crowdfunding y muros de pago; el tercero es la membresía, que permite ser parte híbrida del medio, entre financista, usuario y fanático, con la finalidad de acceder a ciertos círculos que benefician al participante.

Para Charo Sábada (2016:253), el modelo de negocio en los cibermedios va más allá de la monetización, ya que el trabajo en red permite tener una plantilla básica de redactores, lo que también implica una precarización del trabajo, pero genera posibilidades de ser más versátiles y flexibles a la hora de innovar con la forma de entregar información.

El crowdfunding, los micropagos, las suscripciones de acceso a información complementaria, son acciones que los cibermedios explotan de acuerdo con su grupo de usuarios, dice Sábada (2016), por lo que la información y su monetización es importante para los cibermedios, pero la oferta hacia los usuarios, tanto en datos como en estructura informativa digital obligan a que los medios se reinventen y busquen nuevas asociaciones estratégicas. 
(...) La información de actualidad corre el riesgo de convertirse en una commodity por la que muy pocos están dispuestos a pagar. Otras iniciativas que añaden elementos de rapidez, o profundidad, o foco, o exclusividad, o interés, están obteniendo mejores resultados (Sábada, 2016:253).

En este sentido, los cibermedios tienen que segmentar muy bien sus audiencias y ofrecer información especializada, para conocer si su propuesta periodística tendrá la capacidad de ser ofrecida por pago o de acceso libre, lo que implica, necesariamente monetizar los recursos del cibermedio y establecer un modelo de negocio aplicable a su realidad, tanto en el contexto de producción, de distribución y consumo, así como en el momento político y económico del país.

De acuerdo con los modelos establecidos, lo que ha primado en los cibermedios del Ecuador ha sido el publicitario, como lo analizaron Punín, Martínez y Rencoret (2013), quienes hacen un estudio de la situación de los medios digitales en el país a partir de la aplicación de las diez tendencias digitales establecidas por Cerezo-Gilarranz, especialista en estrategias.

Los cibermedios ecuatorianos colocan publicidad en sus plataformas de acuerdo a una pauta anual y aún no han llegado al modelo de mantenimiento de clientesanunciantes por clic. Del análisis realizado, el Estado ecuatoriano es el mayor inversionista en publicidad de los cibermedios analizados y muy pocas firmas fuertes e independientes del gobierno son parte de los clientes que anuncian en estos medios (Punín, Martínez y Rencoret, 2013:205).

El modelo de los medios patrocinados no es tan expandido, pero existen cibermedios financiados por instituciones nacionales o extranjeras, que es donde se ubica la cooperación internacional con sus líneas de apoyo al desarrollo de agendas informativas relacionadas con los ODS y los derechos humanos, así como el fortalecimiento a la democracia y las libertades.

Más allá de los modelos de negocio y sostenibilidad de los cibermedios, Campos Freire (2015) establece diez puntos que los metamedios (Manovich, 2008) deben tener en cuenta para enriquecer su credibilidad como capital social, reputación y confianza en los mediadores, que son los periodistas y de esta manera configurar su propio modelo de negocio:

1. Plan differentiated general strategies for each platform and adequate contents for different publics and channels.

2. Research and verify information according ethical standards and techniques and semantic tools or available big data.

3. Plan and reorganize production process according platforms and editions.

4. Produce, write and edit stories in genres, narratives and technologies according to the public focus and the platform's target (print, broadcasting, web, cellphone or social network). 
5. Creating and coordinating research and development teams, data engineering, multimedia, design, marketing, sales and advertising.

6. Manage and run the distribution and diffusion of the stories of each channel.

7. Promote synergies of distribution and diffusion through platforms and networks.

8. Following and using the whole information cycle of the different platforms.

9. Listen to the digital conversation, talk and attend to the participation users.

10. Collect, filter, process and analyze the data of the digital interaction for informative planning and the commercialization of journalist activity. (Campos Freire, 2015:114-115)

\section{Cooperación en Ecuador: 10 años de control estatal}

Los 10 años de gobierno de Rafael Correa (2007-2017) se caracterizaron por una confrontación constante con la prensa, que puede explicarse desde dos perspectivas. La primera es la politización de la información, que Rincón (2010) la atribuye a la fascinación que tienen los gobiernos por la lógica mediática y el interés de los medios de comunicación por no perder sus privilegios y el dominio de la opinión pública.

La segunda se sustenta en las investigaciones de Carlos de la Torre (2015) sobre la destitución de los presidentes ecuatorianos Abdalá Bucaram en 1997, Jamil Mahuad en 2000 y Lucio Gutiérrez en 2005, en la que dice que los medios de comunicación asumieron un rol político al tomar posiciones contrarias a estos presidentes.

En cuanto al tema de la cooperación, hay que realizar algunas puntualizaciones de tipo histórico sobre la teoría de las relaciones internacionales, para, en ese contexto, tratar de explicar la visión del gobierno del Ecuador, respecto a esta materia.

Para ello, primero se partirá de la teoría realista de las Relaciones Internacionales y de los planteamientos de Morgenthau (2015), respecto a que la ayuda exterior es controversial, pese a que tiene su propia finalidad y justificación, que va más allá de la política exterior:

"Desde este punto de vista, este tipo de ayuda se considera el cumplimiento de una obligación de unas pocas naciones ricas hacia otras muchas pobres. Por otro lado, no se ve la ayuda exterior como algo justificable en absoluto y, de hecho, se reputa un enorme despilfarro que no sirve ni los intereses de Estados Unidos ni los de las naciones que la reciben" (Morgenthau, 2015: 148).

De acuerdo con este mismo autor, hay seis tipos de ayuda que se entrega por parte de los países cooperantes, especialmente Estados Unidos: ayuda exterior humanitario, la ayuda exterior de subsistencia, la ayuda exterior militar, la ayuda a la lucha contra la 
corrupción, la ayuda exterior para lograr prestigio y la ayuda exterior para el desarrollo económico. Sin embargo, según Morgenthau (2015), la única ayuda que alcanza la característica de ser apolítica es la humanitaria.

Un aspecto más que hay que destacar sobre la cooperación internacional es la que realizan las organizaciones privadas que, también, es atribuida a los gobiernos de sus países y con "sus relativos efectos positivos o negativos, en la medida en que el país destinatario o sus habitantes perciban que la ayuda humanitaria de un país extranjero está desempeñando una función política" (Morgenthau, 2015: 149).

Desde una visión liberal, como lo señala Jiménez González (2004), y con base a los acontecimientos históricos de la década de los 80 del siglo anterior (fin de la Guerra Fría):

La principal preocupación de esta corriente ha sido la incapacidad del Estado para asimilar la modernización, es decir, la forma en que ésta se expresa en el dilema de hacer compatible democracia y mercado y cómo afecto ello los ritmos de la cooperación. Lo anterior ha permitido el surgimiento de teorías integracionistas que se pronuncian por una colaboración ramifica transnacional para hacer frente a problema comunes, es decir, parten de la idea de que cooperar en un sector lleva a los estados a contribuir también en otros sectores (Jiménez González, 2004: 124).

A partir del fin de la Guerra Fría hasta la actualidad, de acuerdo con el liberalismo, en la política internacional intervienen no solo los estados, sino otro tipo de grupos como los transnacionales y las organizaciones no gubernamentales y gubernamentales y "tanto el transnacionalismo como la interdependencia son dos conceptos fundamentales" (Jiménez González, 2004, pág. 5) y llevan a entender bajo esa lógica a la cooperación.

Una teoría alternativa a esta es la marxista, que plantea la teoría de la dependencia, respecto a la cooperación, y señala que esta "en sus múltiples modalidades, no había cumplido con dos objetivos principales: coadyuvar a la movilización de recursos internos y contribuir al progresivo alivio del estrangulamiento exterior" (Hodara, 1987: 120).

Se mencionan estas tres líneas históricas, ya que el gobierno de Rafael Correa, dio un giro a la política internacional del país, que llevó a que también cambien las reglas para la cooperación internacional. Esos cambios constan en el Plan Nacional de Desarrollo (2007-2010), presentado durante la campaña presidencial del 2006 y que se profundizan para 2008, luego de que entrará en vigencia la Constitución aprobada en ese año.

Un artículo de El Telégrafo, escrito por Rodríguez Gelfenstein (2013) y reproducido en el portal web de la Cancillería señalaba que los objetivos que se perseguían era:

(...) fortalecer un orden internacional multipolar, desarticular viejos colonialismos y robustecer alianzas prioritarias, insertar al Ecuador estratégica y soberanamente en el mundo y priorizar la integración latinoamericana, establecer como premisa de la integración el ejercicio de la soberanía de forma amplia y solidaria donde cada pueblo tenga la capacidad de auto determinarse, privilegiar el impulso a la 
integración Sur-Sur, salvaguardar la intención del Estado ecuatoriano de reestructurar el sistema de acumulación, distribución y redistribución de las riquezas, promover una nueva arquitectura financiera internacional, establecer acuerdos comerciales colocando especial énfasis en la necesidad de sustituir selectivamente las importaciones y proclamar la movilidad humana (« Ecuador una política», en El Telégrafo, 2013).

En el Plan Nacional de Desarrollo (2007-2010), en cambio, se señalan dos objetivos, dos políticas y una meta en torno a la cooperación. Los objetivos son el 5 y el 11. El primero es garantizar la soberanía nacional, la paz y auspiciar la integración latinoamericana y el segundo, establecer un sistema económico solidario y sostenible.

Las políticas fueron la 11.25, que planteaba alinear la política exterior con la política interna y rendir cuentas a la ciudadanía. Y la 11.28, que establecía la adecuación de la cooperación internacional a las necesidades de "inversión social, productiva y ambiental del Plan Nacional de Desarrollo") (Plan Nacional de Desarrollo, 2007: 277).

Para conseguir estas dos políticas se trazaron como estrategias la ampliación e impulso a las relaciones Sur-Sur en el continente, la elaboración del Plan Nacional de Cooperación Internacional y la puesta en marcha de mecanismos para monitorear y evaluar a la cooperación para que "responda al interés nacional y permita ajustes periódicos" (Plan Nacional de Desarrollo, 2007: 277), es decir, reforzar al Sistema Ecuatoriano de Cooperación Internacional.

En cuanto a las metas, se planteó la 5.6, que señalaba que se debía dinamizar las relaciones bilaterales con los países vecinos.

Ayllón y Dolcetti (2014) dicen que el giro de la política exterior y consecuentemente a la revisión de la cooperación que había recibido el país, hubo una serie de gestos políticos, que tuvieron un peso simbólico:

1. Expulsión de los soldados de Estados Unidos de la base aérea de Manta.

2. Rechazo a las iniciativas de libre comercio impulsadas por Estados Unidos.

3. Ingreso del Ecuador a la Alianza Bolivariana para los Pueblos de Nuestra América (ALBA).

Sin embargo, hubo otros gestos adicionales que mostraron este giro en la política exterior. Valga citar lo que se presentó como logros de política exterior y que constan en el último informe a la nación presentado en 2017 por Correa:

Se dinamizó y promovió la Cooperación Sur-Sur en un escenario de cambios trascendentales en el ámbito de la cooperación internacional, que se ha convertido en un eje fundamental de la política ecuatoriana, ya que se presenta como una modalidad alternativa a la cooperación norte-sur. [...] El Gobierno ecuatoriano [...] entregó cooperación sin condicionamiento alguno a pueblos que lo requerían. La experiencia nacional, relacionada con exitosas políticas públicas, fue compartida con gobiernos de la región como Haití, Cuba, San Vicente y las Granadinas, entre otros. [...] El liderazgo de Ecuador, en el ámbito multilateral, se reflejó en su elección como presidente del 
G77+China, durante 2017. En el contexto de la Organización de Estados Americanos, Ecuador ha impulsado un fortalecimiento del Sistema Interamericano de Derechos Humanos, a través de una mejora de los procedimientos y la institucionalidad (Informe a la Nación, Senplades, 2017: 174).

También surgió la Agencia Ecuatoriana de Cooperación Internacional (AGECI), creada mediante Decreto Ejecutivo N. 699, del 30 de octubre de 2007, y su objetivo fue implementar "las estrategias generales de cooperación internacional, las políticas y reglamentos de gestión, el desarrollo y aplicación de instrumentos de gestión del Sistema Ecuatoriano de Cooperación Internacional" (Registro Oficial No 113, 2007). Este organismo, vía Decreto Ejecutivo No. 429, del 15 de julio del 2010, publicado en el Registro Oficial 246 del 29 de julio de 2010, cambió su denominación por la de Secretaría Técnica de Cooperación Internacional (Seteci). Esta última se encargó de que se cumplan con los decretos ejecutivos 16 y 739, del 4 de junio de 2013 y del 3 de agosto de 2015, respectivamente, que tuvieron como objetivo regular y registrar a las corporaciones, fundaciones, organizaciones sociales, sean de carácter nacional o internacional o que tengan fines de gestión o control social.

Adicionalmente hay que señalar que algunos de los periodistas que renunciaron a los medios de comunicación masivos, sea por razones personales o presiones políticas y, frente al cierre de otros medios privados, por causas financieras, miraron en el espacio digital una opción para continuar con su labor. Algunos de los medios que surgen en esta década son GK City, La Barra Espaciadora, La República; 4Pelagatos; Plan V; MilHojas; La Posta.

\section{Cooperación internacional y periodismo digital en Ecuador}

En los diez años, motivo de este estudio, se puede decir que la cooperación internacional se canalizó a través de dos organizaciones que trabajan en la libertad de expresión y de prensa en el Ecuador. La primera es la Fundación Andina para la Observación y Estudio de Medios (Fundamedios), fundada en abril de 2007. Y, la segunda, el Foro de Periodistas del Ecuador (FOPE), que surgió en 2012, pero que obtuvo su personería jurídica en 2014.

Sus representantes, César Ricaurte (Fundamedios) y Pamela Cruz (FOPE), coinciden en que la base para la obtención de fondos en el exterior fue su trabajo directo con los donantes internacionales, vía participación en concursos con temáticas específicas que presentan las organizaciones, para que los interesados participen.

A grandes rasgos, la cooperación internacional funciona con donantes que son los sistemas de cooperación de países europeos y Estados Unidos. Luego están los grandes donantes privados, por ejemplo, la Open Society, que está vinculada al fondo de inversión de George Toros, que trabaja específicamente con los temas de libertad de expresión, justicia y fortalecimiento democrático. Estos grandes donantes llaman a licitaciones en las cuales concursan grandes ONG, de carácter internacional, que son como intermediarias, y pueden acceder a esas licitaciones, ya que tienen la capacidad operativa para cumplir los requisitos de los donantes. Estas intermediarias entran en contacto con las operadoras, que son las ONG locales. Fundamedios es una ONG que 
está en el terreno y entonces nos aliamos con distintas organizaciones grandes, para ejecutar proyectos (Ricaurte, 2019).

Cruz (2019) explica que esos fondos, en el caso de FOPE, corresponden a tres proyectos relacionados con capacitación y la escritura de textos académicos sobre la prensa en el Ecuador. Sus principales aportantes fueron las embajadas de Estados Unidos (a través del Departamento de Relaciones Internacionales y de Comunicación) y Canadá (con el departamento de Comunicación, que continuamente informa sobre los énfasis que necesitan) y los organismos no gubernamentales -como Freedom House- que les interesaba temas vinculados a la libertad de expresión, periodismo y legislación. Con Naciones Unidas, a través del departamento de Comunicación, consiguieron financiamiento para la parte logística de cursos, material, capacitadores, entre otros.

Las temáticas de los cursos fueron: seguridad digital, emprendimientos digitales, libertad de expresión y periodismo. Sus proyectos los desarrollaron en Quito, Guayaquil, Latacunga y estuvo dirigido a periodistas, profesores de periodismo y medios de comunicación en general. Las estimaciones del FOPE es que hubo trabajo directo con 22 medios, entre nacionales y comunitarios (Cruz, 2019).

Fundamedios y FOPE concuerdan que para obtener resultados positivos en la consecución de fondos deben estar pendientes de los intereses específicos que tienen los distintos gobiernos. Hasta la finalización del gobierno de Correa, los temas eran libertad de expresión, pero luego ha habido interés por temas vinculados a la lucha contra la corrupción y el sistema democrático.

Ricaurte (2019) explica que, en el caso de Fundamedios, los donantes, durante esta década, han sido Open Society Institute, que luego se convirtió en Open Society Fundation, la CAF - que es la gran financista de la Fundación Nuevo Periodismo Gabriel García Márquez, FNPI-, Fundación Avina, la National Endoment for Democracy (NED) y la Unión Europea. Han sido entre 3 hasta 22 donantes, aunque Ricaurte (2019) destaca que en los momentos más tensos de la relación Correa-prensa, algunas ONG decidieron abandonar el país.

Esta búsqueda de fondos en el extranjero también obedece a la poca cultura de donaciones internas (Ricaurte, 2019), ya que el sector privado no aporta a la sociedad civil. Y, la otra vía, el gobierno, no era viable por la relación tensa con los medios de comunicación, los dirigentes sociales y de la sociedad civil, especialmente con quienes trabajaban en libertad de expresión, información y prensa.

Los primeros fondos que recibió Fundamedios se dedicaron a proyectos de autorregulación y los códigos de ética mediáticos. Este proyecto contó con el apoyo de la Asociación Ecuatoriana de Editores de Periódicos (AEDEP) y algunas universidades de Quito y Guayaquil. También se trabajó en defensores de audiencia y observatorio de medios. Este último proyecto se convirtió en el más importante por el nivel de incidencia que logró (Yépez, 2019). 
Concretamente, la información obtenida por ese observatorio sirvió de base para la realización de los informes de las relatorías de libertad de expresión y de prensa de las Naciones Unidas (ONU) y de la Organización de Estados Americanos (OEA) que, a su vez, mostraron su preocupación por lo que ocurría en el país, especialmente en los documentos que corresponden a los años 2012, 2015 y 2017 (Yépez, 2019).

Otro de los proyectos, en el cual hubo una alianza con la FNPI, fue el diálogo binacional de directores de medios, que se dio luego del ataque de Angostura, a fin de frenar la escalada verbal entre Ecuador y Colombia (Yépez, 2019).

Otros programas que se desarrollaron, entre 2009 y 2012, fue de capacitación intensiva en periodismo digital, de investigación y acceso a la información. Ricaurte estima que hubo 2300 periodistas capacitados en esos años. También aportaron con el capital semilla para el surgimiento de los medios digitales Plan V, GK City y 4Pelagatos, y entre finales de 2016 e inicios de 2017, hubo fondos de hasta 2000 dólares para periodistas que buscaban impulsar investigaciones de mediano y largo plazo.

En la primera etapa de apoyo a los medios de comunicación, hubo un escenario particular de cierre de medios y atentado a la libertad de expresión o censura. Esto generó un ecosistema donde emergían distintas iniciativas de periodismo independiente, que tenía como finalidad seguir haciendo el periodismo, más cuando la Ley de Comunicación no alcanzaba a los medios digitales. Al ser un ecosistema nuevo tampoco había un modelo de financiamiento ni monetización, son medios que se inician solo con periodistas, es decir sin un equipo de mercadeo ni con dinero. Fundamedios aportó con fondos semilla [...] Más adelante surgen los proyectos de trabajo colaborativo o en red, que se trata de publicaciones que se difundían a través de estos mismos medios (Yépez, 2019).

En suma, Fundamedios (Yépez, 2019) tiene varias áreas de trabajo: a través de la red de monitoreo reporta las posibles violaciones a las libertades de expresión y de prensa. Observatorio de medios, que monitorea a los medios, las publicaciones o intervenciones que tienen que ver con libertad de expresión y de prensa; de aquí surgen estadísticas para producir informes puntuales. También está pendiente de la coyuntura política, económica y social, es decir, de los temas sobre los que habla la sociedad, para publicar un informe anual sobre opinión pública.

Una tercera área de trabajo es Ecuador Chequea, que verifica datos y discurso público. La cuarta es Fundamedios Estados Unidos, que reporta las posibles violaciones a la libertad de expresión o prensa en América Central y Estados Unidos; Voces del sur, proyecto regional en América del sur, en donde siete países unificaron sus indicadores de agresiones y se publica a través de una web sus resultados (Yépez, 2019).

\section{Los casos de estudio: Mil Hojas y Código Vidrio}

\section{Mil Hojas}

La Fundación Mil Hojas, como así se denomina el cibermedio en la URL www.milhojas.is tiene un dominio de Islandia (is). El cibermedio está construido en una plantilla de WordPress y su última publicación es del 20 de agosto de 2019. 
El espacio digital no cuenta con información institucional sobre la Fundación ni existen imágenes con enlaces a financistas; tan solo un enlace gráfico con Plan V, otro portal informativo. Tiene cinco secciones: Expedientes, Reportajes, Quién es quien, Por la boca y Otras miradas, que al dar clic sobre sus hipervínculos no lleva a ninguna sección, sino que refresca la página inicial; lo mismo sucede con la barra de navegación inferior, que está en inglés.

Estructuralmente, su interfaz de página de incio, presenta cinco niveles de información, en donde en el que se encuentra debajo de la barra superior de navegación, se encuentran los temas más actuales con trabajo de diseño gráfico, que llevan a la información anunciada.

Los demás niveles de información muestran destacados de cada una de las secciones de la barra de navegación superior, con jerarquía informativa: construcción gráfica de la más actual o importante y entrada con titular, fotografía y lead, en los demás casos.

Imagen 1: Interfaz de home page
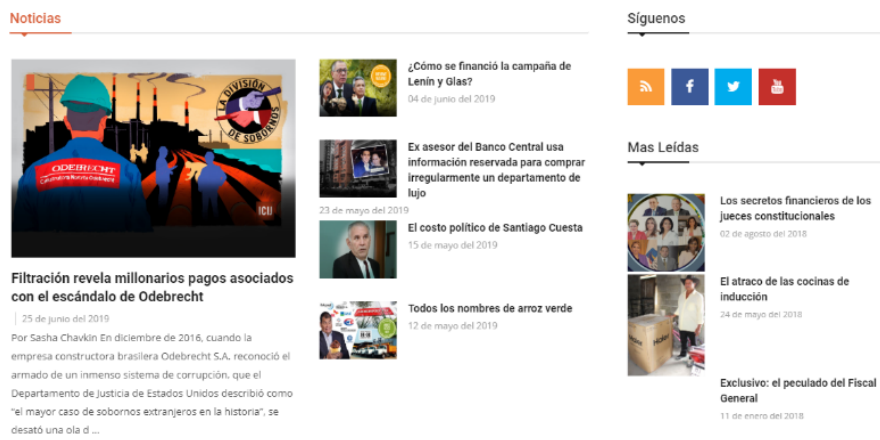

Fuente: www.milhojas.is

En cuanto al uso de multimedia, el cibermedio trabaja con fotografía e infografías, únicamente, pues todas las notas van acompañadas de imágenes que muestran a los actores o bien establecen esquemas para mejor comprensión del lector, lo que indica que el cibermedio es comprendido como un medio tradicional, sin desarrollo de infografías animadas, vídeo o audio que complemente las historias.

El espacio digital tiene asociadas cuentas en Facebook, Twitter y YouTube. 


\section{Imagen 2: Diseño de infografía}

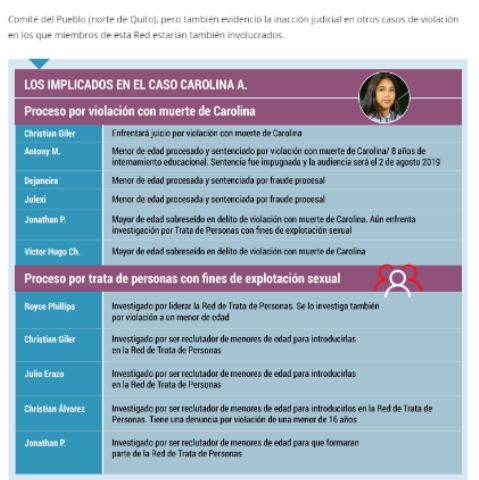

Fuente: www.milhojas.is

Hay que destacar que el cibermedio presenta documentos oficiales en formato .pdf con marca de agua de La Fuente -medio de investigación periodística asociado al político Fernando Villavicencio- para que el lector compruebe que el trabajo de investigación está fundamentado en documentos de acceso público o bien han sido obtenidos mediante trabajo con fuentes confiables.

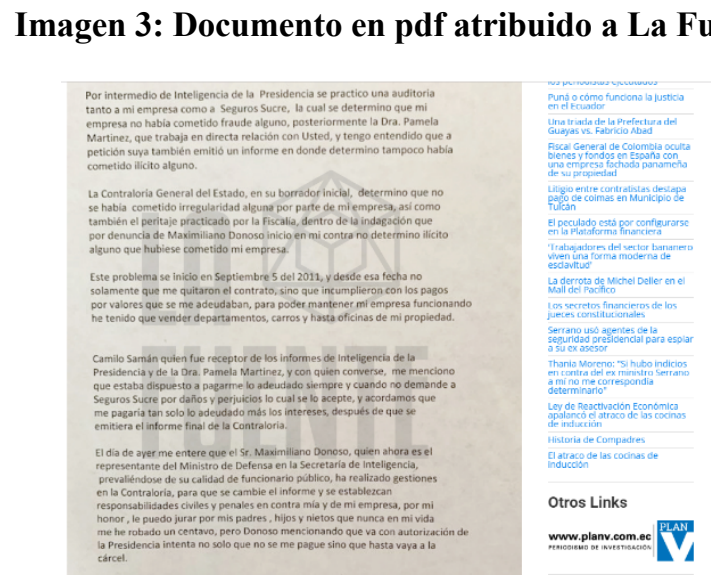

Fuente: www.milhojas.is

En el cibermedio no hay firmas de responsabilidad individual o personal, tan solo Redacción Mil Hojas es la responsable de todo el manejo informativo.

La información política es el eje de este cibermedio, que está asociado a la figura y al trabajo del periodista Christian Zurita, de larga y reconocida trayectoria, principalmente por haber participado junto a Juan Carlos Calderón, en la investigación sobre los contratos del hermano del ex presidente Correa.

\section{Código Vidrio}

En la URL www.codigovidrio.com, Arturo Torres y María Belén Arroyo firman como los responsables de la información publicada en esta plantilla modificada de 
WordPress. Ambos periodistas tienen larga trayectoria en el periodismo impreso y de investigación, lo que le proporciona identidad y reputación al proyecto periodístico.

De acuerdo con su declaración de principios en la sección ¿Por qué Código Vidrio?, existen dos componentes para el desarrollo del proyecto en espacio digital:

El proyecto tiene dos componentes fundamentales. Una plataforma de búsqueda documental, que conduce al lector a información relevante de esta investigación. El buscador intenta ser amigable y sencillo.

El segundo eje es el despliegue de varias historias en profundidad. Intentamos demostrar no solamente los intereses ocultos, sino las conexiones políticas y económicas detrás de los personajes. Sobre todo, mostrar que los casos de corrupción no son episodios aislados: responden a una práctica sistémica (www.códigovidrio.com).

Las secciones de este espacio digital son tres: ¿Por qué Código Vidrio?; Historias, con las subsecciones Historias de Rehenes, Historias de Odebrecht y Otras Historias; y, Buscador de documentos claves, que funciona como un repositorio a partir de los temas abordados en las historias.

Imagen 4: Repositorio de documentación

Documentos claves
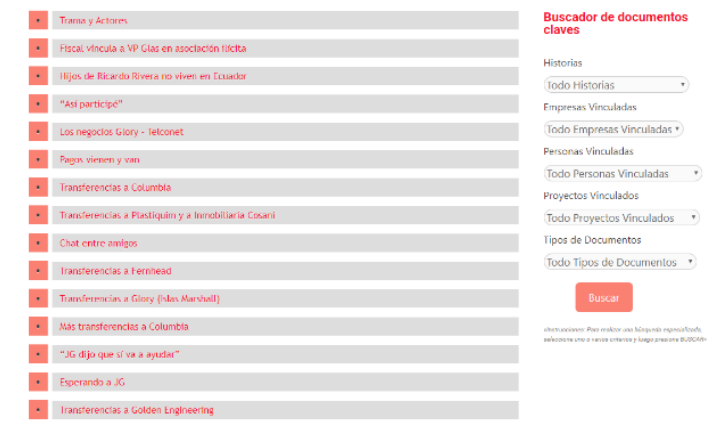

Fuente: www.codigovidrio.com

Al igual que Mil Hojas, este espacio digital está pensado desde el periodismo impreso, pues no incorpora el lenguaje hipertextual ni multimedia, salvo algunos audios incrustados; carece de infografías animadas, pero la estructura de los textos es para lectura en pantalla con párrafos cortos y énfasis en palabras y nombres.

El uso hipertextual de la información está relacionada con la sección Documentos clave y muchos de ellos envían a información publicada en otra secciones y entradas, lo que hace que la lectura sea endogámica y no existan asocios externos, tanto de producción informativa como de difusión. 

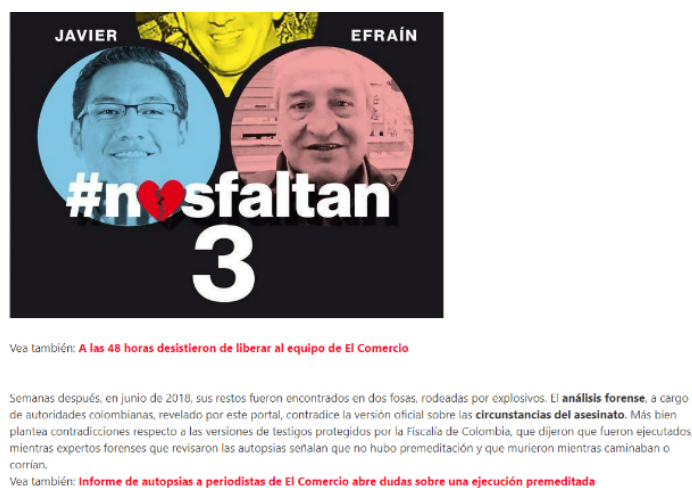

Fuente: www.codigovidrio.com

La interfaz gráfica y la usabilidad del sitio es muy sencilla y rápida al cargar, pero al igual que Mil Hojas, no existe una innovación periodística en tratamiento ni plataforma, pero sí en lo referente a la temática, ya que es de los pocos espacios que se especializa en corrupción estatal y seguridad pública, dejando de lado la información generalista.

El espacio digital tiene asociadas cuentas en Facebook, Twitter, YouTube, Gmail, Pinterest y WhatsApp.

\section{Las agendas y la cooperación como forma de sostenibilidad}

El surgimiento de los medios digitales en Ecuador tuvo, para los periodistas Christian Zurita (2019) y Arturo Torres (2019), un importante impulso en la necesidad de contar historias que estaban quedando por fuera de los medios tradicionales durante la década en que gobernó el expresidente Rafael Correa Delgado.

Ambos hacen especial énfasis en esa particularidad, tampoco dejan de lado la influencia que han tenido - a escala mundial- las nuevas tecnologías, la masificación de las redes sociales y las consecuentes diversas formas de comunicarse. Este contexto también ha ido mermando el espacio y la preponderancia de la que, hasta hace poco, gozaban los medios tradicionales.

Arturo Torres (2019) apunta que la lógica de informarse cambió radicalmente a partir del año 2000. Las personas empiezan a consumir noticias a través de medios digitales y así se origina el abandono paulatino de los medios tradicionales. A su criterio, este último aspecto comenzó en Ecuador entre el 2006 y 2007. Para entonces algunos periódicos y canales de televisión tenían su portal web. Además, recuerda Zurita, se instauraron los primeros medios digitales que agregaban información, pero no generaban contenido propio y no pudieron crecer.

Los cambios que la sociedad iba experimentando a la hora de informarse se vieron alimentados por un factor coyuntural: la relación beligerante que el expresidente Rafael Correa mantuvo con los medios de comunicación tradicionales. Torres (2019) recuerda 
con precisión el primer gran escándalo que enfrentó el exmandatario fue las relaciones que altos funcionarios de su gobierno mantenían con las Fuerzas Armadas Revolucionarias de Colombia (FARC) y que empezaron a salir a la luz a partir del bombardeo en Angostura. "Ese es el primer escándalo que desnuda a Correa y que le da el campanazo de lo peligrosa que puede ser la prensa" (Torres, 2019).

Otro caso que golpeó al anterior régimen fue, precisamente, de autoría de Christian Zurita (2019): los millonarios contratos suscritos entre el Estado y Fabricio Correa, hermano del entonces primer mandatario. Un tema con el que, nuevamente, el Gobierno sintió el peso del periodismo independiente.

Esos ejemplos solo atizaron el ataque a la prensa desde el gobierno. Insultos a medios y periodistas, prohibición de que los integrantes de su gabinete otorguen entrevistas, quitar a los medios privados la publicidad gubernamental y restringir el acceso a la información pública fueron algunas de las acciones que se implementaron afectando la libertad de expresión y promoviendo la censura. A esto se suma el excesivo gasto gubernamental en propaganda y la construcción de un aparataje mediático afín al correísmo. De forma paralela, Rafael Correa presionaba para la aprobación de la Ley de Comunicación, cuyo objetivo era controlar los contenidos de los medios (Torres, 2019).

"Fue un ataque sistemático que se llevó a cabo en los países bolivarianos", afirma Torres (2019) y como consecuencia, "teníamos los días contados en los medios de comunicación tradicionales", concluye Zurita (2019). Por ello a medida que el gobierno se consolidaba en el poder y hacía de la censura una política de Estado, los periodistas se vieron volcados a buscar o construir espacios para seguir dando a conocer su trabajo e investigaciones.

Esta búsqueda, a criterio de ambos, también se dio como producto de la batalla interna que se libraba en los medios de comunicación privados. Con la Ley de Comunicación aprobada, en las diferentes redacciones se vivía un proceso de autocensura y luego, en palabras de Christian, de acostumbramiento a las nuevas reglas del juego. La noticia se limitó a repetir lo que las autoridades decían en las ruedas de prensa. Para evitar conflictos, rectificaciones forzadas, juicios y diferentes represalias del régimen, quedaron por fuera de la agenda mediática las investigaciones en contra del Gobierno y sus posibles casos de corrupción.

Ese fue el momento, coinciden los periodistas, en que los medios digitales quedaron como la última y única alternativa porque escapaban al control instaurado con la Ley de Comunicación. "El Internet nos salvó la vida”, dice Christian Zurita (2019).

En el caso ecuatoriano los periodistas que dejaron los medios tradicionales y empezaron su camino en lo digital, lo hicieron bajo diversas circunstancias, en distintos momentos y con enfoques particulares. Al respecto, Christian Zurita (2019) relata que mientras aún estaba colaborando en un renombrado periódico nacional (El Universo), con un grupo de personas interesadas en seguir trabajando por un periodismo independiente, 
comenzaron a esbozar la idea de tener un portal web en el cual se publiquen los temas e investigaciones que ya no tenían cabida en los medios tradicionales.

Fue así que, en un proyecto piloto, impulsado por un periodista de Colombia, se publicó la investigación sobre el plagio de la tesis de grado de los hermanos Vinicio y Fernando Alvarado, colaboradores de primera línea del expresidente Correa. Sin embargo, esa información no duró mucho y fue bajada de la web (Zurita, 2019).

Con esa experiencia, el portal Mil Hojas se constituyó como un proyecto reservado y $\sin$ nombres. Fue "una página constituida en Islandia con todas las posibilidades de seguridades para que nadie pueda conocer de dónde se construyen esos contenidos" (Zurita, 2019). Mil Hojas arrancó y posteriormente, Zurita decidió dejar su lugar en el periódico y apostar por este proyecto.

El caso de Arturo Torres (2019) fue distinto. Primero dejó el periódico donde trabajó por 18 años (El Comercio) luego de que, en sus palabras, había concluido su ciclo y consideraba que el ambiente no era el idóneo para seguir adelante con el trabajo de investigación característico suya. Esto debido a los cambios y ajustes en la línea editorial, dictada por el nuevo dueño del medio. Al salir, junto a su esposa que también es periodista, valoraron las posibilidades que tenía Internet y decidieron lanzarse con la publicación del tema Odebrecht, que Arturo tenía avanzada. Crearon, entonces, el portal Código Vidrio.

Ambos periodistas entienden al periodismo digital como una alternativa con un sinfín de posibilidades y aunque ven coincidencias en algunos aspectos con el periodismo tradicional, también aprovechan las diferencias.

Christian Zurita (2019) es determinante: "Yo mismo me pongo el tema, me apruebo y publico No tengo que preguntar a nadie. Me expreso en mi totalidad, sin ningún tipo de restricción", (Zurita, 2019).

Agrega que un factor que sí ha cambiado en lo digital es la contrastación. En Mil Hojas no contrastan todo lo que publican ya que la mayor parte corresponde a denuncias de corrupción. Estas, afirma Zurita, se sustentan en los propios documentos que se hacen públicos en el portal. Según indica, si buscarían contrastar todo con funcionarios o exfuncionarios de Gobierno, los temas quedarían congelados. A eso se suma la seguridad de los periodistas: "Si yo me pongo a contrastar cómo se robaron 28 millones de dólares, a mí me matan. Tengo que publicarlo. Es un tema de supervivencia”, manifiesta Christian.

De su lado, Arturo Torres (2019) es más cauto. En efecto coincide en que el periodismo digital brinda una libertad que no se tiene en los medios tradicionales, donde hay varios filtros para dar paso a una publicación. Pero a su criterio ese factor lo obliga a ser mucho más responsable y sacar una historia sólida, totalmente contrastada y verificada. En el Internet, agrega, ya no se busca "golpear" a otro medio con una exclusiva; sino tener una historia que realmente impacte e interese. "Ahora que camino solo, tengo más cuidado. Escribo de manera más prolija, dedico más tiempo. Los medios 
digitales nos permiten movernos más a los enanos digitales, que a los medios tradicionales", sostiene.

Estos periodistas, en sus respectivas páginas, han optado por diferentes líneas de contenido. Ambos declaran que ellos mismo son quienes definen de qué se va a hablar, cómo se construye la agenda, a quién se le da voz y cuándo publicar.

Para Arturo Torres (2019) el contenido de Código Vidrio se ha ido formando en el camino. Su página inició con un tema de Odebrecht que él había estado trabajando desde que seguía en su anterior periódico. Después de publicarlo escribió otro que resultó necesario dado la coyuntura: la muerte de tres periodistas ecuatorianos en la frontera norte.

En su paso por los medios tradicionales, Torres (2019) se había especializado en temas de seguridad, frontera norte, policías y militares. Él conoce estas áreas informativas, tiene contactos y fuentes que le brindan valiosa información. Por ello, decidió seguir aprovechando el camino que cultivó en los medios tradicionales, y explotar en lo digital esas mismas temáticas.

Zurita (2019) sostiene que también aprovechó su experiencia en investigación de casos de corrupción. En particular en torno a funcionarios del correísmo. Este material informativo, afirma, ha llegado a publicarse en el portal Mil Hojas, ahora llamado Periodismo de Investigación, porque se acumuló durante la década del gobierno de Rafael Correa en que sucedieron muchas cosas que los medios no publicaban por censura y por todo el aparataje instaurado para encubrir información pública.

Bajo estos antecedentes, ambos periodistas se ratifican en que ellos dictan la línea editorial de sus medios digitales. Torres (2019) lo hace junto a su colega y esposa, María Belén Arroyo (revista Vistazo); y Zurita (2019), comparte responsabilidad con Fernando Villavicencio, quien es la otra cara visible del medio. Los periodistas entrevistados niegan la posibilidad de que, detrás de estas iniciativas informativas, haya aportantes dictando los contenidos.

Christian Zurita (2019) dice que su portal tiene financiamiento internacional de la National Democracy Endowment, entidad a la que presentaron el proyecto que tienen en funcionamiento. Además, "hemos tenido el financiamiento de personas particulares que han colaborado. Han sido voluntades que no han podido formalizarse en acuerdos económicos normales como contratos", (Zurita, 2019).

Arturo Torres (2019) indica que de momento su portal no tiene ningún financiamiento externo. Sostiene que en estos dos años la página ha subsistido con los recursos propios. No obstante, admite que están en busca de establecer un modelo de negocio que les permita mantener la absoluta independencia editorial. En esa búsqueda contemplan la posibilidad de tener financiamiento de entidades privadas y organizaciones no gubernamentales (ONG). Pero, hasta la fecha de realización de esta entrevista, nada se ha concretado. 
Para Zurita (2019), el hecho de que algunas ONG decidan poner recursos en ciertos medios digitales tiene que ver con la comprensión de que "el periodismo juega un papel preponderante en el activismo social" (Zurita, 2019). Torres (2019) se pronuncia en sentido similar y considera que estas organizaciones trabajan por el interés público y "saben que los medios de comunicación somos necesarios para fortalecer la democracia con una buena información” (Ibid).

Para ambos periodistas la apuesta que hacen las ONG también tiene que ver con la calidad de contenido que se generan en los medios digitales. Y en la actualidad, coinciden, es desde estos espacios desde donde se marca la agenda nacional y se genera opinión pública, logrando mayor impacto en esas áreas en relación a los medios tradicionales.

\section{Conclusiones}

Los modelos de negocio de los medios digitales, establecidos por Picard (en Pavlik, 2008), han sufrido una mutación en su estricta aplicación, pues como bien lo establece el propio Pavlik (2008) y Campos Freire (2015) las formas de financiamiento y sostenibilidad tienen que ver con los contextos propios de los cibermedios, en este caso, la agenda política y gubernamental potenció la existencia de los medios en plataformas digitales y la búsqueda de auspiciantes para temáticas de largo trabajo como la investigación periodística es aún la fórmula principal para el trabajo de periodistas con reputación nacional e internacional.

El modelo alternativo, sumado a la búsqueda de auspicio es, entonces, la forma más adecuada para el periodismo digital de investigación, ya que los otros modelos no son viables, ya que la producción periodística y el tratamiento informativo y despliegue de formatos de Mil hojas y Codigo Vidrio no son para el entorno ciento por ciento digital, ya que no configuran verdaderos metamedios, como lo establece Campos Freire (2015) en sus diez puntos de desarrollo de los metamedios.

De esta manera, los cibermedios de investigación son considerados, por sus propios productores y administradores, como repositorios de información, banco de datos y fuente de otros medios tradicionales, debido a la reputación de sus periodistas y a la ausencia de unidades de investigación periodística en espacios informativos de radio, tv y prensa impresa.

El desarrollo de prácticas investigativas tiene una relación inversamente proporcional con el desarrollo de las plataformas digitales, pues de los diez puntos establecidos por Campos Freire (2015), ambos cibermedios estudiados cumplen con dos de los elementos: la verificación ética de los datos y la fuentes, y producción organizada en la plataforma, pero no existe una convergencia integrada de géneros y formatos distribuidos en varios canales, y producidos para tales espacios. El periodismo digital es incipiente, pero la información es valiosa. 
La cooperación internacional como auspiciante para el periodismo de investigación en cibermedios tiene que establecer estándares de calidad de producción, distribución y conversación, pues los productos periodísticos presentan calidad en el tratamiento de la información y los propios periodistas aseguran que al no tener dependencia de un dueño de medio, son más libres al momento de trabajar y tienen mayor responsabilidad social, lo que corrobora lo planteado por el propio Picard (en Campos Freire, 2015) al asegurar que la forma de pago por contenido es una vía importante para el desarrollo del ciberperiodismo.

La agenda setting de los medios analizados tiene una relación directamente proporcional con lo que establecen Fundamedios y FOPE, al ser estos grupos colegiados los mediadores de la cooperación y canalizar los fondos de acuerdo con lo establecido por los donantes. De esta manera, los temas de los cibermedios investigativos son derechos humanos, libertades y lucha contra la corrupción.

\section{Bibliografía}

Ayllón, B. Y Dolcetti, M. (2014). La cooperación para el Buen Vivir de Ecuador (20072014). Respuestas al consenso neoliberal y recuperación del Estado, Revista Relaciones Internacionales. Universidad Nacional de La Plata.

Cazar, A. (2017). Análisis sobre los derechos a la comunicación, ética y retos del periodismo en los medios nativos digitales ecuatorianos. Tesis. Consultado el 23/09/2019: https://dspace.ups.edu.ec/handle/123456789/13611

Campos Freire, F. (2015). “Journalism and Metamedia”. En: López García, X. y Campos Freire, F. (Eds.). Journalism in Change. Media XXI: Porto, p. 91-121.

De la Torre, c. (2015). De Velasco a Correa. Insurrecciones, populismos y elecciones en Ecuador, 1944-2013. Corporación Editora Nacional y Universidad Andina Simón Bolívar: Quito.

Hodara, j. (1987). Prebisch y la Cepal. Sustancia, trayectoria y contexto internacional. El Colegio de México: México.

Jiménez González, C. (2004). Las teorías de la cooperación internacional dentro de las relaciones internacionales. En: Polis 3 (2), págs. 115-147.

Ley Orgánica de Comunicación. Registro oficial n.o 22 Tercer suplemento. Quito, 25 de junio de 2013.

Manovich, L. (2008). Software Takes Command (International Texts in Critical Media Aesthetics). Bloomsbury: New York.

Maciá Barber, C. (2007). "Ética y excelencia informativa: vías tradicionales y fórmulas novedosas para recobrar y consolidar la credibilidad de los periodistas". En: 
Fundación COSO. (Ed.). La ética y el derecho de la información en los tiempos del postperiodismo. Fundación COSO de la Comunidad Valenciana para el Desarrollo de la Comunicación y la Sociedad: Valencia, p. 325-344.

Morán, S. (2019). "El auge de los medios nativos digitales en Ecuador" Plan V [web]. Consultado el 23/09/2019: https://www.planv.com.ec/historias/sociedad/el-augemedios-nativos-digitales-ecuador

Morgenthau, H. (2015). “Una teoría política sobre la ayuda exterior”. En: Relaciones Internacionales 28 (febrero-mayo), p. 147-161.

Rincón, O. (2010). “¿Hay que defender a los medios de comunicación del Estado o al Estado de los medios y de los periodistas?”. En Rincón, O. (Ed.). ¿Por qué nos odian tanto? (Estados y medios de comunicación en América Latina). Centro de Competencia en Comunicación para América Latina y Friederich Ebert Stiftung: Bogotá, p.5-14.

Pavlik, J. (2008). Media in the Digital Age. Columbia University Press: New York.

Portilla Manjón, I., VARA-MIGUEL, A., DÍAZ-ESPINA, C. (2016). "Innovación, modelos de negocio y medición de audiencias ante los nuevos retos del mercado de la comunicación”. En: Sábada, García y Martínez-Costa (Coords.) Innovación y desarrollo de los cibermedios en España. EUNSA: Pamplona, p. 31-39.

Punín, M., Martínez, A., Rencoret, N. (2013). "Medios digitales en Ecuador: perspectivas de futuro", Revista Comunicar.No. 42. DOI: http://dx.doi.org/10.3916/C42-201420 .

Sábada, C. (2016). "Modelos de negocio y coordinación multiplataforma”. En: Sábada, García y Martínez-Costa (Coords.) Innovación y desarrollo de los cibermedios en España. EUNSA: Pamplona, p. 248-254.

Senplades (2007). Plan Nacional de Desarrollo (2007-2010). Senplades: Quito.

(2017). Informe a la nación. Senplades: Quito.

\section{Entrevistas}

Cruz, P. Entrevista realizada en Quito, el 15 de febrero de 2019.

Ricaurte, C. Entrevista realizada en Quito, el 21 de febrero de 2019.

Torres, A. Entrevista realizada en Quito, el 30 de agosto de 2019.

Yépez, D. Entrevista realizada en Quito, el 18 de febrero de 2019.

Zurita, C. Entrevista realizada en Quito, el 24 de agosto de 2019. 